\title{
Digital Supply Chain Management in the Videogames Industry: A Systematic Literature Review
}

\author{
Stephen Kelly ${ }^{1}$ D $\cdot$ Vojtech Kléz| $^{2,3} \cdot$ John Israilidis $^{4} \cdot$ Neil Malone $^{5}$. \\ Stuart Butler ${ }^{6}$
}

Received: 13 September 2020 / Accepted: 22 November 2020 / Published online: 4 December 2020 (c) The Author(s) 2020

\begin{abstract}
As industries mature, they rely more heavily on supply chain management (SCM) to ensure effective operations leading to greater levels of organisational performance. SCM has been widely covered in many industrial areas and, in line with other burgeoning sectors such as Tourism, an industry focus provides the opportunity to look in-depth at the context-based factors that affect SCM. Developments in digital distribution and rapid technological innovations have resulted in an increased focus on Digital Supply Chains (DSCs), which bring about significant changes to how consumers, customers, suppliers, and manufacturers interact, affecting supply chain design and processes. Through a systematic review of the Videogames Industry Supply Chain Management literature, which serves as a pertinent contextual example of a DSC, we look at how supply chains are affected by structural, market and technological change, such as increased platformisation, disintermediation and the proliferation of digital distribution. We distil these findings into a new research agenda, which identifies themes in line with extant DSC research, provides a series of relevant practice recommendations and identifies opportunities for future research.
\end{abstract}

Keywords Videogames · Digital supply chain · Digital distribution · Literature review

Stephen Kelly

stephen.kelly@edgehill.ac.uk

1 Edge Hill University Business School, Ormskirk, UK

2 School of Business, Örebro University, Örebro, Sweden

3 Faculty of Economics, Department of Marketing and Business, VSB-Technical University of Ostrava, Ostrava, Czech Republic

4 Nottingham Business School, Nottingham Trent University, Nottingham, UK

5 Salford Business School, University of Salford, Salford, UK

6 School of Digital, Technologies \& Arts, Staffordshire University, Staffordshire, UK 


\section{Introduction}

Identifying individual parts of a supply chain (SC) is key for increasing organisational performance and achieving greater collaboration and integration (Flynn et al. 2010; Ataseven and Nair 2017). Organisations that engage in effective linkby-link, relationship-by-relationship management can compete more effectively (Lambert and Pohlen 2001) and are better prepared to mitigate risks and overcome unexpected disruption (Kaufmann et al. 2016). However, technology shifts and innovations have brought about significant changes to how consumers, customers, suppliers, and manufacturers interact (Farahani et al. 2017). A greater use of digital distribution, more rapid innovations in technological development and an increase in the customer-driven nature has seen a greater reliance on, and interest in, Digital Supply Chains (DSCs), which affects supply chain design and processes. The adoption of digital technologies has surged in the last few years, and trends point to a sustained acceleration going forward (Büyüközkan and Göçer 2018). Being "born digital” (De Prato et al. 2010), the Videogames Industry (VGI) exhibits key characteristics of a DSC, such as embracing new technologies and changes in consumer behaviour, requiring the redesign of supply chains to adapt (Zinn and Goldsby 2019). VGI supply chains (VGISCs) therefore serve as a pertinent example of a DSC, offering insights for other industries, while reflecting the call for SCM based exploration into other application areas (Asgari et al. 2016).

Now more than ever, gaming is at the heart of the entertainment business. 2.3 billion gamers across the globe spent $\$ 137.9$ billion on videogames in 2018 , an increase of $13.3 \%$ from the year before, with digital game revenues representing $91 \%$ of the global market and half of this coming from the mobile market segment (Newzoo 2018). This has a direct and significant impact on Videogames Industry Supply Chain Management (VGISCM), mainly because the physical boxed product has now been largely eradicated, reducing the reliance on physical distribution and retail and bringing about significant changes to the inter-organisational flows of materials, information and money. Whilst academic interest in videogames has developed over the past 10-15 years, mainly due to the development of the field of Game Studies (Aarseth 2001; Melcer 2015), this is not necessarily true of research concerned with the overall industry (Marchand 2016), with: "...surprisingly little attention from researchers of business and economics" (Zackariasson and Wilson 2012; 1). There is a pressing need therefore for research focused on VGISCM to develop our understanding of what is an increasingly significant industry and also to address the considerable technological developments and displacement of traditional products, coupled with the role of the individual as innovator in what is now a far more dispersed product development process.

To address these motivations, our work develops VGISCM research, with implications for the wider study of DSCs, by mapping, consolidating and evaluating the extant literature to identify gaps for future investigation. It adopts the methodology from Fischl et al. (2014) to perform a systematic literature review, 
applies the generalised maturity assessment framework developed by KeathleyHerring et al. (2016), as a way of organising and presenting our findings, and thematically groups the findings in line with current DSC studies (Farahani et al. 2017). Three research questions were distilled:

- What literature streams and subjects cover the field VGISCM?

- How has the extant literature provided scholarly knowledge on VGISCM?

- What are the key themes/findings present in extant VGISCM literature?

To the best of our knowledge, no literature review conducted thus far has specifically concentrated on VGISCM. This work therefore is valuable for researchers in the field to develop an understanding of these global and complex DSCs. Reflecting greater generalisability, our work is also relevant to those interested in other, similarly disrupted, digitally influenced industries, such as music and other forms of entertainment.

\section{Supply Chain Management}

A SC is the network of organisations that are involved, through downstream (towards the consumer) and upstream (towards the supply market) linkages and SCM is the design, implementation and management of the different processes and activities that generate value in the form of products and services for the ultimate consumer (Christopher 2005). SC studies and analysis allow for the identification, coordination and enhancement of flows of information, material and money (Asgari et al. 2016). The effective use of managing the constituent parts of a SC as well as the integration with other suppliers and customers can have a significant positive impact on a firm's financial performance (Ataseven and Nair 2017; Yu et al. 2013). Further, long-term supplier relationships have both direct and indirect significant effects on operations performance (Prajogo and Olhager 2012).

The study of SCM practices in different industrial sectors allow their special features to be linked to their applied practices and lead to improvements in SCM theories. A range of industrial sectors have been studied, for example, pharmaceutical (Lurquin 1996), automobile (Ramcharran 2006), apparel (Christopher and Peck 1997), chemical (Vlasimsky 2003), healthcare (McKone-Sweet et al. 2005), IT (Yao et al. 2009), telecommunication (Reyes et al. 2002; Catalan and Kotzab 2003), agriculture/food (Cunningham 2001), humanitarian/disaster (Leiras et al. 2014) and grocery (Zairi 1998). Following on from a recent call for further SCM work on emerging trends (Asgari et al. 2016), this study focuses on the VGI, which is technologically fast-paced and has been greatly affected by disruptive innovations, exhibiting the characteristics of a DSC.

\subsection{Digital Supply Chains}

Whilst there is not a fully agreed definition of a DSC, Hoberg et al. (2017) position it within the wider area of digital transformation, which is: “... an organisational change process where digital technologies are used to radically change how a company creates 
value, how it interacts with its customers and business partners, and how it competes in established and emerging markets." (2015: 6). Taking this further, Farahani et al. (2017: 159) see DSC management as: “...leveraging innovative digital technologies to change the traditional way of (1) performing supply chain planning and execution tasks, (2) interacting with all kinds of supply chain participants, and (3) enabling new corporate business models". DSCs exhibit a shift in channel management from conventional, physical distribution to the online (Büyüközkan and Göçer 2018), but still require a focus on how effectively the SC can be managed. DSCs are still in their infancy and whilst offering value opportunities in terms of speed of decision-making, they can make organisations vulnerable by being too data-driven (EY 2016; KPMG 2019). This newness is reflected in the lack of academic literature focusing on DSCs (Büyüközkan and Göçer 2018) and requiring of research into specific contexts and settings to further the field's understanding. VGI can be seen as a pioneer in digitalisation efforts, demonstrating many relevant DSC characteristics, including enhanced and accelerated innovation, personalised experiences, rapid responsiveness and greater flexibility (De Prato et al. 2010). Hence, a contextual study on VGISCM not only provides specific insights for the industry itself but also for other emerging DSCs.

\subsection{Videogames Industry Supply Chains}

Whilst the first videogames originated in university laboratories much earlier, it was arguably not until the late 1970s and early 1980s that there was widespread consumer use of home videogame consoles and computers to play a variety of videogames. The 'videogame crash of 1983' (Cohen 1984; Herz 1997) saw a downturn in the home videogame console market, generally believed to have been caused by poor quality titles and unsuccessful hardware launches. However, this also led to the significant development of the industry in Japan and a subsequent new generation of home videogame consoles. In tandem, home computers as videogame platforms remained commonplace and varied until the late 1990s, which saw IBM PC clones become the dominant home computer platform (Farrimond 2011a, b). A traditional boxed product SC within the VGI can be seen below in Fig. 1.

A more nuanced perspective, representing different dominant countries and the split between hardware and software is shown below in Fig. 2.

The late 1990s/early 2000s began to shape the industry into the form it is today, with Sony's PlayStation 2 gaining dominance before the launch of Microsoft's Xbox. During the subsequent 15 years, increasing home Internet availability and the continued iteration of Microsoft, Sony and Nintendo products (alongside the PC) meant consumers gained greater access to videogame content online (Gretz 2010; Wadley et al. 2003). This content connected consumers to each other, but also to digital distribution

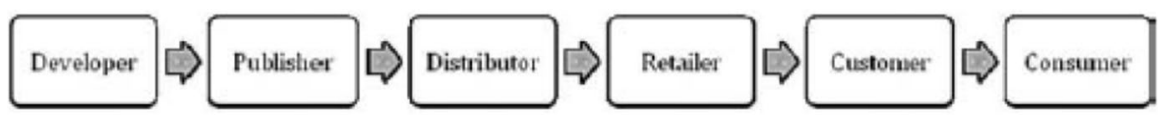

Fig. 1 Traditional supply chain in the video game industry (Zackariasson and Wilson 2012) 


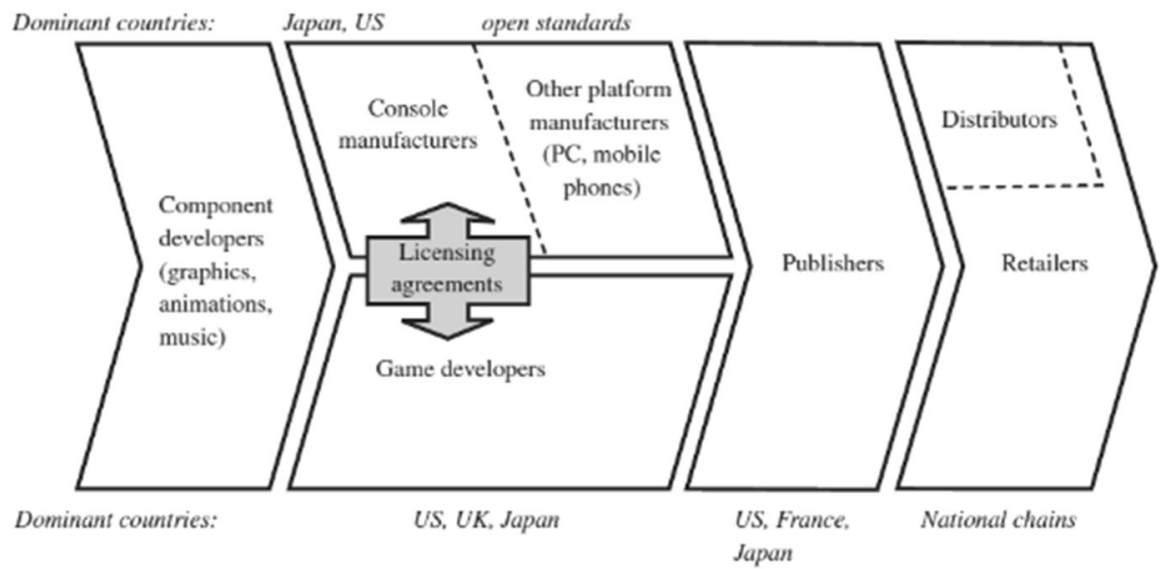

Fig. 2 Enhanced supply chain in the video game industry with dominant countries (Teipen 2008)

platforms such as Steam, Xbox Live and PlayStation network-platforms that distribute products digitally, without the need for a physical boxed product.

Whilst consultancy organisations vary in their estimations, a recent study shows that consumer spend on games will grow to $\$ 180.1$ billion by 2021 (Newzoo 2018). Significantly, videogame sales are rapidly overtaking other entertainment types and in the UK, as an example, the market is now worth more than the video and music industries combined (BBC 2019). Developments in the VGI over the past 10-15 years have seen the proliferation of digital distribution, with $92 \%$ of PC videogames sold globally via digital download (Sacco 2014). According to several sources (Yin-Poole 2013; Francis 2012; Parfitt 2015; Tassi 2018), digital distribution, for example via the Internet platform Steam, was likely to return around $70 \%$ of the retail price to the developer, which is a significant difference to the traditional boxed product SC. In December 2018 this was confirmed by videogames developer Epic when launching their own online videogames store and undercutting Steam, offering $88 \%$ of the retail sale price back to the developer (Tassi 2018; Sweeney 2018). Although there is variation in estimates of the proportion of the sale that a developer receives from retail sales, many sources claim the publisher receives around $30-45 \%$ of the retail price (Yin-Poole 2013, Parfitt 2015), which naturally means the developer receives even less, perhaps as low as 10\% (Edwards 2012).

In addition to the shift from physical to digital distribution, there has also been a significant increase in quasi-self-publishing via platforms such as Steam, which offer developers different distribution options and reduce the need for a traditional publishing house. Figure 3 shows the process of disintermediation, i.e. "removing" organisations from the SC, taking place within the VGI network.

Digital distribution, therefore, subverts the traditional SC and the lines between developer, publisher, retailer and even consumer, become networked, more complex and further blurred. These SC challenges are further compounded by the number of devices in the market that have access to digital distribution platforms for videogames by default (e.g. mobile phones, media set-top boxes such as Amazon Fire, 


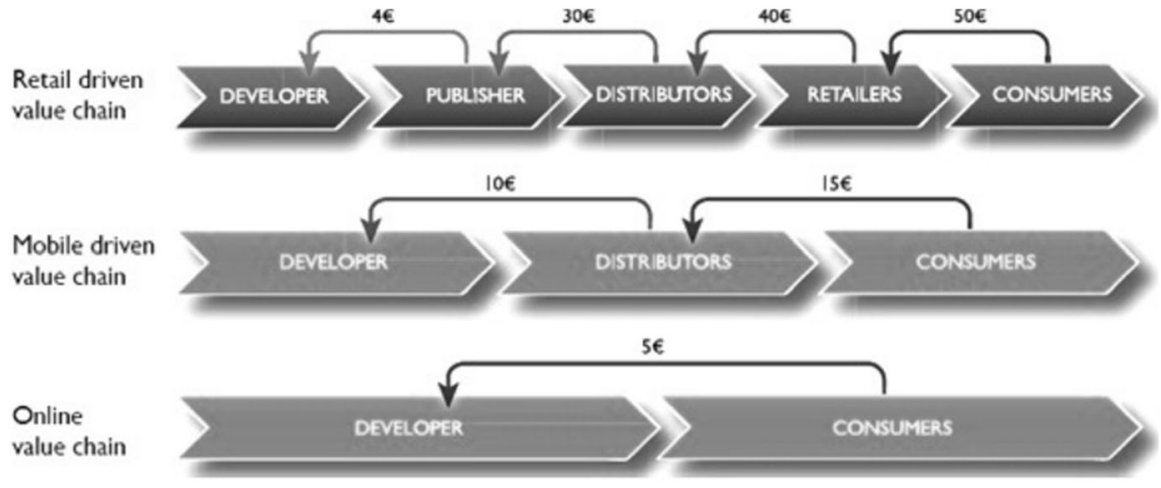

Fig. 3 Supply chain scenarios in videogames (EGDF 2011)

videogames consoles etc.). By way of example, although $91 \%$ of this VG market is from digital videogames, half of this comes from the mobile market segment (Newzoo 2018) and over $90 \%$ of videogames distributed through the Google Play platform are free to download (Statista 2018), relying either on in-game advertising or microtransactions.

The significance of the VGI and the magnitude and speed of technological, distribution and consumer buying behaviour changes, as shown above, mean that there is now a pressing need for research focused on VGISCM. Phenomena such as increased platformisation (Werning 2019) has necessitated SC reconfiguration and the increased reporting of rather alarming work practices in the VGI means that there are real practice gaps in VGISCM (Peticca-Harris et al. 2015). Using the VGI as a focal example of a DSC provides a timely opportunity to use it as an exemplar for other DSCs and the application of DSC principles to the specific context will generate pertinent insights.

\section{Method}

To develop a deep and systematic understanding of VGISCM, we adopt the methodology proposed by Fischl et al. (2014). The focus of our study is to explore extant VGISCM knowledge, thus we have a broad coverage of focal areas. We look at research outcomes, research methods and theories used. The goals are to integrate the extant literature and synthesise the central issues and core themes that the literature deals with. The organisation sets up the structure for the following sections and ensures a coherent approach. Regarding perspective, we have adopted a robust identification and review process to achieve as close to neutral representation and limit biases where possible. Our main audiences are scholars and practitioners in the field and coverage is representative in line with other reviews representing the needs of our audience. 
The EBSCOhost Business Source Ultimate database was selected, and the following keywords were used: Supply Chain Management, Supplier, Supply, Consumer, Market, Network, Transaction, Customer, Value Chain, Governance, Exchange, Purchase, Virtual, Logistics, Digitalisation, Distribution. We used "Boolean/Phrase" search mode and limited our search to English peer-reviewed articles listed in the 2018 Chartered Association of Business Schools Academic Journal Guide (AJG) only (CABS 2018). This search identified 265 papers and these were split evenly across the research team and a consistent set of review criteria was used across the team. A number of papers that were not considered relevant to our phenomena of interest were identified, based on the topics and key findings of each paper. For each rejected paper, the responsible team member specified the reasons and we have shown the main rejection criteria as follows: graphics, technical or hardware related; games used in education; games used as part of experiment/method; VGI market/culture only briefly mentioned; an introduction to a paper or a collection of abstracts; gamification/application of game theory; the papers age makes it no longer relevant due to significant changes in the industry.

The largest area of rejection was those papers that had no real link to videogames, such as Andersen et al. (2007) and Stewart et al. (2011) or those such as Olsen and Lanseng (2012), which only briefly mentioned the VGI. These were picked up in the search due to occasional use of the word 'game' or the papers bibliography's including sources where the terms 'game' and/or 'supply chain' featured. There were also a set of papers that used a game as part of the experiment or method, such as Acquisti and Spiekermann (2011); Chiaravutthi (2007); Kempf (1999); Markovitch et al. (2015). After this review, 111 papers were identified as being relevant for a detailed analysis. To provide a robust structure for our findings, we use the generalised maturity assessment framework developed by Keathley-Herring et al. (2016) as a way of organising and presenting these. The Keathley-Herring et al. (2016) framework is based on a review of other maturity frameworks and results in nine dimensions of research area maturity, with 24 unique criteria. These dimensions are: Genesis of the area; Author characteristics; Publication characteristics; Research design characteristics; Theoretical characteristics; Content characteristics; Impact; Diffusion; and Infrastructure.

The analysis process for each of the papers was based on a descriptive one for the more quantitative findings and thematic analysis for those that required a more qualitative approach aiming at giving a broader focus (Patton 2002). To provide a more focused and DSC relevant set of content characteristics, we follow the approach of Derwik and Hellstrom (2017: 202) in that an: "interpretative synthesis was applied based on the core content of the publications and the questions driving their research" and thematically group the findings in line with current DSC studies (Farahani et al. 2017). To ensure greater levels of objectivity and inter-rater reliability, multiple members of the research team reviewed each paper and we held cross-coding meetings to highlight potential discrepancies and resolve any differences. 


\section{Findings and Discussion}

This section takes each of the first seven dimensions of maturity identified in the framework developed by Keathley-Herring et al. (2016), as a way of organising and presenting our findings from the systematic literature in a robust manner. Under dimension 6 (content characteristics), we make use of the extant DSC literature to inform the structure of our thematic findings. These gaps are then distilled into a structured research agenda at the end of the paper.

\subsection{Dimension 1: Genesis of the Area}

Although videogames were first commercially released in the 1970s and gained significant commercial success in the 1980s and 1990s, academic research into VGISCM tends to be a fairly recent phenomenon, as shown in Fig. 4.

An early notable exception is Durgee (1984), in which the author discusses methods increasing the value of "computerised products", which includes videogames, by making them more stimulating and fun to use. Similarly, Dixon and Karboulonis (2000) were among the first to notice the growing importance of DSCs, calling for research in this field and application of existing marketing theories in the field. The first empirical research on our list (Gallagher and Ho Park 2002) explores the factors influencing the market success of the first six video game console generations, noticing that the VGI is highly networked through the relationships between console manufacturers and independent game developers. The console manufacturers who attract independent game developers to make more complementary products (videogames) for the console tend to gain a larger installed base. Furthermore, the VGI is highly innovative, although the timing of the innovation, rather than being first to the market, tends to be a more successful strategy.

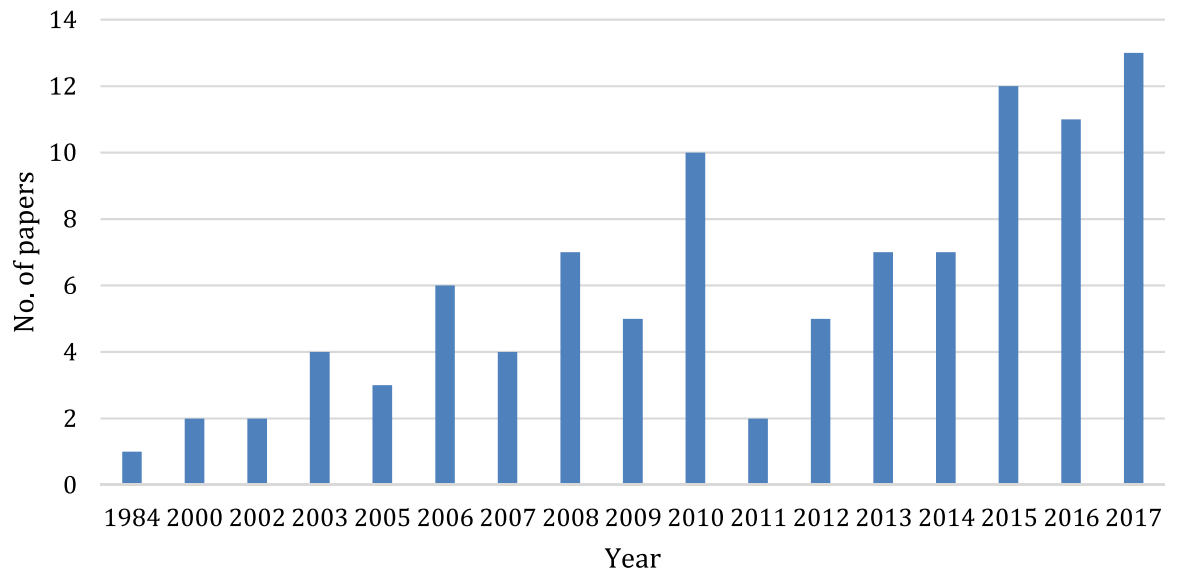

Fig. 4 Number of papers per year 


\subsection{Dimension 2: Author Characteristics}

Although on an upward trend, the results show that authorship in the field is relatively concentrated, with a small set of core authors that publish most often, although there is a regular influx of new authors per year. 11 authors have published more than one paper which suggests that the area is relatively well developed with a small, but stable, set of 'experts' that publish in this field. In addition, there is an increase in the trend of multi-author papers, with $74 \%$ of them being co-authored, which may indicate a growing maturity of the VGISCM field. We also found that $60 \%$ of the lead author's institution country was either the United Kingdom or United States and an over-reliance on the work of a limited number of countries can be seen as potentially limited. However, we suggest that this is perhaps more likely to be merely a reflection of the strength of VGI development in these countries and the geographical proximity of research institutions to these countries.

\subsection{Dimension 3: Publication Characteristics}

The characteristics of where (the journal) work has been published is a useful indicator in determining the current and future research direction. The clustering properties of the AJG were influential in determining the relevant review streams, as keywords derived directly from the articles did not allow for an appropriate mapping and grouping of the streams, as there was very little consistency in terms of the subjects and/or areas listed. Figure 5 gives the breakdown by discipline, as per the 2018 AJG subject area classification.

Almost half of the publications reviewed (45\%) were published in Marketing and Economics journals. Our more detailed review of themes discussed later shows

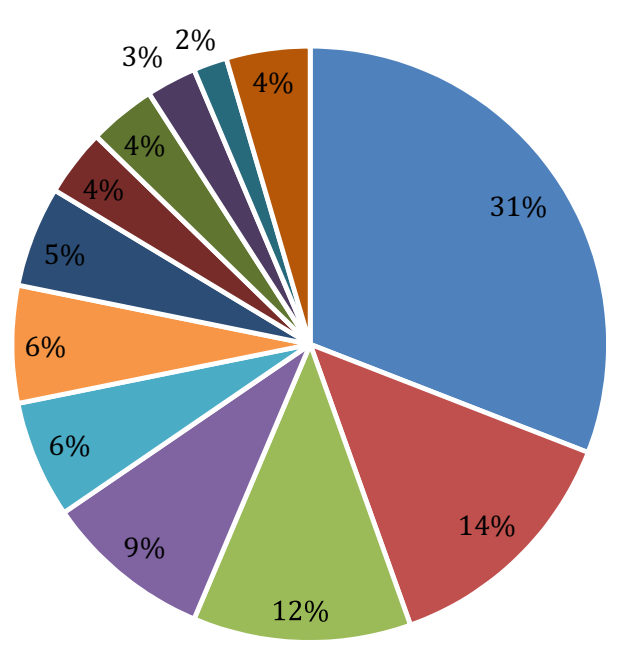

Fig. 5 Breakdown of VGISCM research by discipline

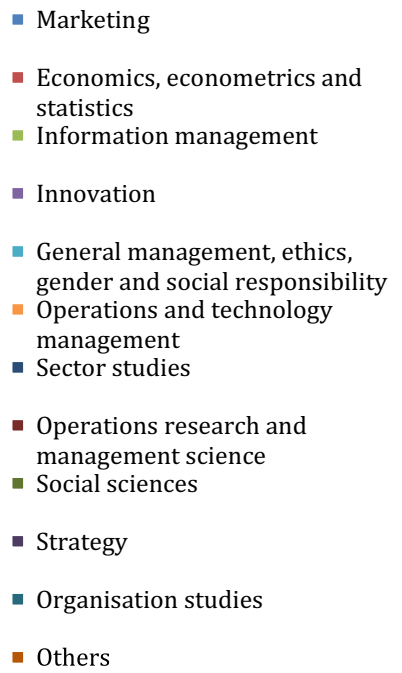

- Marketing

- Economics, econometrics and statistics

Information management

Innovation

General management, ethics, gender and social responsibility Operations and technology

management

- Operations research and management science

- Social sciences

Others 
that VGISCM research has mainly taken a consumer purchasing behaviour perspective, often looking at the role of gamers in the development of both products and distribution networks. The very low representation of publications listed within the Operations Research and Management Science (6\%) suggests that VGISCM warrants further study, particularly from a multi-organisational SCM perspective, which is of particular relevance when considering the wider impact of DSCs. Analysis of individual journal titles reveals that there is no single dominant outlet preferred for publication, although the International Journal of Research in Marketing was the most preferred outlet with 6 articles published overall, closely followed by Research Policy and the Journal of Consumer Behaviour both having 5 articles each. The majority of outlets only appeared once in the analysis, showing a lack of clarity and focus around where VGISCM research sits and how it can best be targeted for future developments. From a citation perspective, the most cited paper (1535 citations) was from the Marketing category and looks at how online reviews can influence sales of VGI products (Zhu and Zhang 2010). The second most cited paper (865 citations), comes from the Economics category and reviews two-sided markets, of which videogames can be an example (Rysman 2009). Reflecting on the publication trend discussed above, it is clear that scholars tend to cite publications mainly around Marketing and Economics, often overlooking areas of Operations Management and other fields.

\subsection{Dimension 4: Research Design Characteristics}

$53 \%$ of research in VGISCM was empirical, with $31 \%$ of papers using a modelling approach and $16 \%$ being conceptual. We also looked at the trends over time for these characteristics and found that empirical research has increased since the formal start of the study into the area. The vast majority of the empirical papers (70\%) adopted a quantitative methodology, with $24 \%$ and $6 \%$ being qualitative and mixed methods respectively. In this analysis, we see a move away from a clear emphasis on conceptual papers in the early days to one that uses both qualitative and quantitative approaches, which would indicate a development of the maturity of the field. A range of research methods have been used, but incorporating more rigorous methods and the inclusion of more advanced mixed-methods studies would undoubtedly benefit the field.

\subsection{Dimension 5: Theoretical Characteristics}

In almost two thirds $(64.42 \%)$ of papers, there was no mention of theory, with the remaining papers using one theory $(25.96 \%)$ or multiple $(9.62 \%)$ theories. Also, there was no single dominant existing theory used among the papers that specified one. The Industrial Marketing \& Purchasing (IMP) theoretical framework was the most used, although with only five papers in total (Corts and Lederman 2009; Dubé et al. 2010; Mai et al. 2011; Steiner et al. 2016; and Song et al. 2017). Other theories that were used more than once are signalling theory (Cox and Kaimann 2015; Li and Yi 2017), product lifecycle theory (Healey and Moe 2016; Marchand 2016) and 
cannibalisation theory (Wenqi and Altinkemer 2008; Li and Yi 2017). Many of the "grand theories" in other SCM focused research (Spina et al. 2016) are rarely used (e.g. Transaction Cost Theory, Social Exchange Theory), with limited exceptions being the resource-based view and dynamic capabilities in Li et al. (2010).

\subsection{Dimension 6: Content Characteristics}

A key aspect of our study is to identify the thematic terrain of the extant work and we have done this in two ways. First, we identified how the papers were split between their focus on internal (e.g. intra-organisational), dyadic (e.g. between two organisations) and the wider SC (e.g. encompassing multiple organisations). This shows that $9.5 \%$ of these were internal (intra-organisational), 56\% dyadic and $34 \%$ $\mathrm{SC}$ focused and therefore, there is considerable opportunity to consider the wider $\mathrm{SC}$ aspects. This is of particular importance in an industry that is fragmented, affected by rapid technological changes and where organisational activities are fluid and boundaries can change quickly. We then used inductive category development (Mayring 2000) through a detailed thematic analysis of each of the papers to identify the main themes. To provide some structure to our thematic analysis and generalisability to a wider range of DSCs, we have thematically grouped our findings according to the DSC characteristics identified by Farahani et al. (2017: 160).

\subsection{Performing Supply Chain Planning and Execution Tasks}

In this category, we identify the rapid rise of the prosumer, in which consumers can use different means to engage in videogame co-creation and how this creates different requirements for SC planning and execution. For example, Arakji and Lang (2007) illustrates how organisations are effectively outsourcing some development activities to the consumers. This shows that new activities, individuals and organisations can emerge quickly in highly distributed, technologically driven SCs and that supplying organisations can more effectively and efficiently harness their resources (e.g. consumer understanding of VG requirements and trends) if they can take early advantage and have knowledge of what activities can be formed.

Unsurprisingly, there were a number of papers that covered logistics and delivery aspects, such as the increase in digital distribution in comparison to physical models (Waterman and Wook 2012), the ability for content producers to bypass traditional publishers (Broekhuizen et al. 2013; Dixon and Karboulonis 2001) and logistics models of retailers such as Blockbuster (Chung et al. 2011). From a planning perspective, there are a number of papers that analyse the effect of timings of product release (Dew and Ansari 2018; Ho and Hanssens, 2017) and versioning (Cox 2017).

A key aspect of SC planning and execution is the product development process and we saw two sub-themes emerge. First, papers which look at capabilities, such as creativity (Aoyama and Izushi 2003) and inter-firm mobility (Storz 2015) and then, second, country effects on these capabilities (Anderton 2017) and the effect of nation or supranational employment and labour regulation on those working in development fields (Teipen 2008, 2016). This area therefore covers the type of 
people who are involved in the creative and innovative aspects of game design and country-specific environments, which can foster or hinder these developments.

\subsection{Interacting with All Kinds of Supply Chain Participants}

With greater digitalisation, communication becomes more rapid and easier for a wider variety of SC participants to engage in. There are papers which look at the effect and power of consumer reviews and word of mouth on pricing and consumer behaviour (Hervas-Drane 2015; Cui et al. 2012) and those that establish a relationship between perceptions of product quality and consumer buying intentions (Cox 2014; Claussen et al 2015). These papers show that consumers in the VGI can wield significant power oversupplying ones in their interaction with the resources of the product. Information, in the form of reviews and other considerations, flow towards the supplying organisations and may have pricing or product development implications.

There are also a significant number of papers which cover direct network effects, which is where consumers place greater value on products with a large network of other users (McIntyre and Srinivasan 2017), whereas indirect network effect (i.e. based on a large variety of complementary products) is covered in the next category. Work in this area also highlights intra-consumer interactions between gamers and within gaming communities, meaning that online videogames are socially driven and, although attachment with videogames is important, the relationships forged with fellow players drive consumption behaviours (Badrinarayanan 2015). Some papers examine engagement with videogames and focus on the experience itself, normally with role-playing videogames e.g. active escapism as a means of coping (Kuo et al 2016) and their immersive qualities (Kuo et al 2017). This highlights the range of reasons behind the use of VGs and indicators of buying intentions and is therefore useful knowledge that can be used by supplying organisations and other prosumers in VG creation and co-creation.

\subsection{Enabling New Corporate Business Models}

A significant theme covering the interrelationships between the complementary nature of hardware and software was identified, specifically showing indirect network effects, i.e. originating from interdependencies between the consumption of one product/service and the consumption of complementary goods and services. They occur when a higher diffusion of goods/services results in a broader variety of additional goods or services. Consumers place greater value on products with a large network of other users and a large variety of complementary products (McIntyre and Srinivasan 2017). To this effect, a growing body of literature has examined the interaction between software supply and console adoption (Clements and Ohashi 2005; Gretz 2010; Kim et al. 2014). Respectively, Sun et al. (2016) note the effects of breadth and depth of software variety on consumer hardware adoption in the fifth-generation video game market. McQuilken et al. (2015) discuss ways to positively influence consumers' product evaluations through bundling of hardware and 
software as well as time-limited promotions. Papers in this area also focus on product 'tying' activities, such as distributing videogames that can only be used on certain compatible hardware (Steiner et al. 2016) and the effects of breadth and depth of software variety on consumer hardware (Sun et al 2016). Derdenger (2014) elaborates on the concept of 'tying' and the intensity of price competition which occurs when a console hardware manufacturer produces software that is incompatible with rival hardware. Similarly, Derdenger and Kumar (2013) highlight the dynamic, long-term effects of bundling on demand. It is evident therefore that the increasing prevalence of non-exclusive software gives rise to indirect network effects that exist between users of competing and incompatible hardware platforms (Corts and Lederman 2009).

Complementary product portfolios not only influence the adoption of platforms by individuals but also affect sales of consoles within this platform-mediated market (Cenamor et al. 2013; Healey and Moe 2016). Mai et al. (2011) note ways of upselling products, looking at initial positioning of primary products (e.g. Microsoft or Sony products) and then further sales of complementary products (e.g. through purchasing Xbox360 or Wii afterward). Also, as videogames are primarily distributed in digital data form, they can only be used on compatible hardware, hence network effects can drive the diffusion of such systems (Steiner et al. 2016). Regarding the adoption of certain platforms in particular, technological change brings a dynamic perspective to this trade-off as it renders existing technology obsolete but also increases the performance of the complementary products, therefore increasing market potential (Claussen et al. 2015). Maruyama et al. (2015) highlight that wider availability of titles on a platform positively motivates further game developers to affiliate with the platform, thus creating an important indirect network effect. There are a number of papers that highlight different business and strategic opportunities, such as those that look at the effects of branding in videogames, demonstrating both the growth in opportunities for companies (Farrand et al. 2006), the development of advergames (Çeltek 2010), analysing how product placement in videogames affects brand attitude and brand recall (Mackay et al 2009).

There are also a group of papers that look at market entry characteristics, such as disruptive innovation (Sun and Tan 2012), barriers such as network effects (Schilling 2003) and incomplete market information (Pan 2017). As Wenqi and Altinkemer (2008) note, competitors jockey to position themselves as the first-mover within a generation or wait and enter the market with cheaper and more advanced technologies. Similarly, determining market prices before product launch (Zufryden 2007) and using exclusive contracts in vertical relationships between the platform provider and software supplier (Prieger and Hu 2012; Cox 2014) can be challenging and therefore create additional barriers to entry. The rapidly expanding network of platform users and the use of complementary applications to capture entire markets or block entry has also been highlighted (Schilling 2003; Meagher and Teo 2005; Cennamo and Santalo 2013). Further complicating the SC structure, VG platforms compete for software publishers, and gamers may invest into in-house publishing of their own software (videogames) before they enter competition (Thomes 2015). Balland et al. (2016) notes that as the industry is getting more mature, network ties over short geographical distances are more common, which is due to the increase in 
technical complexity of game development. Vaan et al. (2014) examine the effects of cognitive distance on the success of video game developers, finding that structural folding (the overlap of a membership in a cohesive group with another cohesive group) is of the utmost importance in the video game industry.

\subsection{Dimension 7: Impact}

To assess publication prominence of the field, the five AJG quality rating categories were used. Ranging from 1 (lowest) to $4 *$ (highest), this classification is based upon peer review, editorial and expert judgements following from the evaluation of publications, and is also informed by citation impact factors. Overall, there has been an increase in the quality levels of the journals being published in, with a clear increase in 2 and 3-rated publications, with $28 \%$ of VGISCM papers found to be published in 2-rated journals and 26 percent in 3-rated journals respectively. Also, the majority of 4-rated journals have been published very recently. Looking at the top five mostcited VGISCM articles, analysis of author prominence characteristics, such as number of citations, h-indices and i10-indices, indicates that scholars contributing to the field are very prominent and well-established academics. Specifically, data retrieved from Google Scholar show that on average each author has been cited by at least 6093 other papers. Although the sample of authors reviewed does not cover the full extent of our work, the findings coupled with the analysis around research impact and publication prominence, appear to suggest that there are significant opportunities for VGISCM research to increase its impact.

\subsection{Contributions and a new research agenda}

Looking at the context of VGISCM has allowed us to analyse a specific industrial setting in considerable depth while illustrating key characteristics of DSCs. Our work was primarily stimulated by the need to provide the basis for a new research agenda for an economically and socially important industry, which is highly distributed, fast-changing and complex and is affected by disruptive innovation and the blurring of organisational boundaries. Our findings show that there is a paucity of literature that considers the wider aspects of VGISCM, particularly around the need to rethink how SCs in this context are structured and function. We also see that there are further opportunities to increase the maturity of the field and this first systematic treatment provides a useful contribution in positioning this new research agenda with current theory while offering guidance on where to focus thematically, methodologically and theoretically.

We have identified a significant emphasis in the Marketing field and specifically on consumer-related research. Whilst this work is important in understanding what motivates and influences consumer buying decisions and behaviour, there are opportunities to extend this perspective to also cover inter-organisational interaction and the wider SC. Doing this will allow for an analysis of the overall industry and provide insights into its complexity and fluidity. In addition, further research could go beyond traditional literature reviews and look specifically at the diffusion, e.g. a 
variety of communities of practice and infrastructure dimensions, e.g. the number of academic programs/degrees that cover VGISCM. As the VGI exemplifies some interesting and novel characteristics (e.g. fast-moving disintermediation and fluidity of SC structure), it provides a unique setting for study that other industries and markets can learn lessons from.

To further synthesise the findings and draw the themes together, we have developed a representative model (Fig. 6), which shows the interrelations and themes discovered in the thematic analysis, specifying the SC actors and linkages. In this model, various network effects should be examined in future research. For example, the more developers embrace a digital platform (e.g. by signing an exclusive contract, or by creating a platform of their own), the more the final customers are motivated to use this platform. This then creates another network effect, as users are more likely to use the platform, when their friends are already using it, further increasing the value. The same could be said about the interaction of game developers and hardware manufacturers-console manufacturers very often rely on firstparty studios (such as the acclaimed Naughty Dog studio for Sony) or exclusive videogames from third-party developers.

Methodologically, the timing of research in the field is critical as technology and consumer trends develop rapidly and thus more frequent research is needed. For example, the potential flat rate fees identified in Marchand and Hennig-Thurau (2013) are now a reality (e.g. EA Origin Access and XBox Game Pass) and this means that care needs to be exercised when over-relying on the extant literature. A more developed field would make use of sophisticated research methods and, although there has been an increase in these, there are opportunities to make use of mixed methods and more advanced statistical analysis techniques. These aspects should also facilitate publication in more demanding journals and increase the impact of the research.

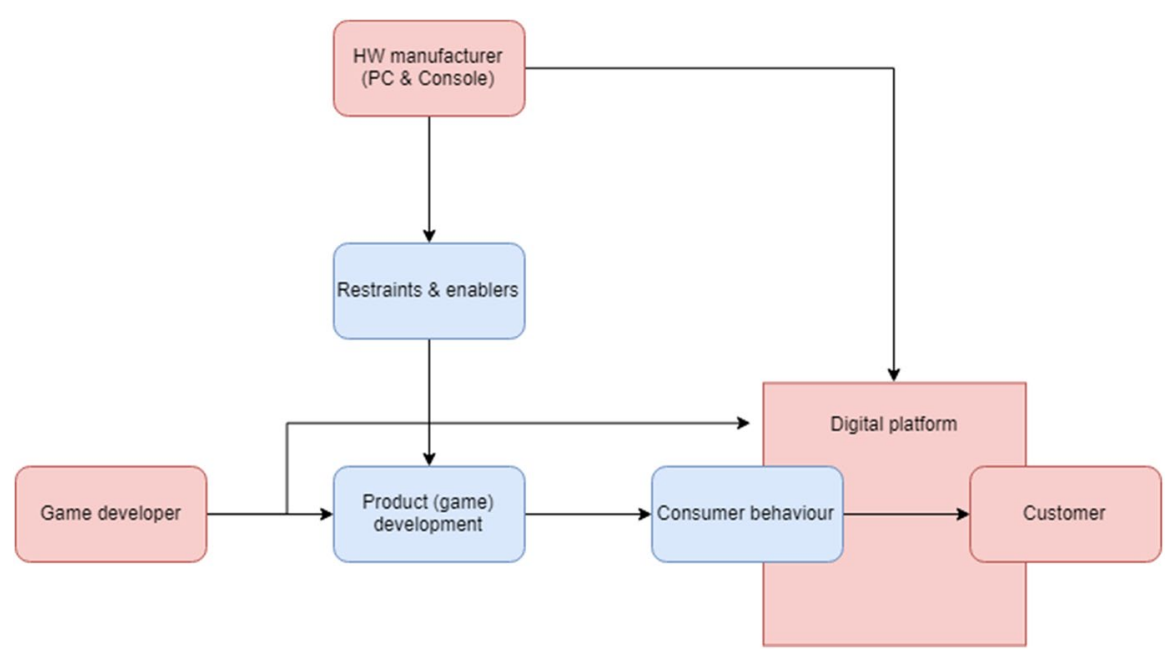

Fig. 6 Integrated network model representing the current state of the literature 
From a theoretical perspective, it was evident that there is a relative lack of theoretically underpinned research, particularly using "grand theories". Using such theories may provide opportunities for research being published in higher quality journals and raise the profile and impact of research in this area. Similarly, a greater convergence on a set of relevant theories will also allow for more theory development and refinement to take place, which will further develop our understanding of the area and also contribute to the wider area of SCM. The extant literature suggests that network approaches might also be useful in examining the SCs of disrupted industries. In the thematic analysis, it was revealed that those industries are dominated by various networks and interactions, e.g. hardware and software manufacturers, user networks or virtual markets such as Steam. Interestingly, although extant papers research and mention those effects, network theory or other theories on intracompany and market relationships, such as social exchange theory, are seldom mentioned. We believe that operationalising those theories for use not only in VGISCM but other disrupted and digitalised industries would help us gain further insight into the dynamics of DSCs.

Finally, as informed by Büyüközkan and Göçer's (2018), we identify several practical implications and recommendations. DSCs require adapted organisations and culture; as we have highlighted the increased digital awareness and engagement of consumers, there is a pressing need for executives and SC managers and executives to develop similar capabilities. This may necessitate changes in the hiring process (through revised job descriptions) and adaptations in organisational training programmes to reflect these requirements. This also relates to the implications for the digital customer experience, in which customisation and personalisation play an increasing role. Specifically, understanding the customer through customer touchpoints, the customer buying behaviours through customer analytics, active engagement with social media and other communications media, as well as harnessing the role of embedded branding, should lead to greater levels of customer satisfaction and build brand loyalty. Digital operations need to be fully embedded into an organisation's processes and practices, for example making use of big data and cloud computing technologies to allow organisations to respond quickly and in an agile manner to consumer requirements.

\section{Concluding Remarks}

Through the mapping, consolidation and evaluation of relevant academic VGISCM literature, we critically review recent developments in the field and draw out generalisable DSC themes. We have developed a relevant framework to help in better understanding and managing global and complex DSCs, while providing recommendations for practice and future research. As with all literature reviews, the collection of papers is done at a certain point in time and, as this is a fast-moving field, additional studies will have been published since our collection process that could help inform this debate. We also limited our study to academic papers and a wider review, encompassing grey literature from practice publications, would undoubtedly generate additional findings. 
Acknowledgment This contribution was created within the project SGS funded by Faculty of Economics, VŠB-Technical University of Ostrava, project name Identification of Reference Groups Roles in Buying and Consumer Behaviour, project registration number SP2018/125.

\section{Compliance with Ethical Standards}

Conflict of interest On behalf of all authors, the corresponding author states that there is no conflict of interest.

Open Access This article is licensed under a Creative Commons Attribution 4.0 International License, which permits use, sharing, adaptation, distribution and reproduction in any medium or format, as long as you give appropriate credit to the original author(s) and the source, provide a link to the Creative Commons licence, and indicate if changes were made. The images or other third party material in this article are included in the article's Creative Commons licence, unless indicated otherwise in a credit line to the material. If material is not included in the article's Creative Commons licence and your intended use is not permitted by statutory regulation or exceeds the permitted use, you will need to obtain permission directly from the copyright holder. To view a copy of this licence, visit http://creativecommons.org/licen ses/by/4.0/.

\section{References}

Aarseth, E. (2001). Computer game studies, year one. Game Studies: The International Journal of Computer Game Research 1(1). http://www.gamestudies.org/0101/editorial.html.

Acquisti, A., \& Spiekermann, S. (2011). Do interruptions pay off? Effects of interruptive ads on consumers' willingness to pay. Journal of Interactive Marketing, 25(4), 226-240.

Andersen, L. P., Rasmussen, J., Chan, K., \& Tufte, B. (2007). Tweens and new media in Denmark and Hong Kong. Journal of Consumer Marketing, 24(6), 340-350.

Anderton, D. (2017). Changing leadership in peripheral city region development: The case of Liverpool's high technology sectors. local economy. The Journal of the Local Economy Policy Unit, 32(4), 352-373.

Aoyama, Y., \& Izushi, H. (2003). Hardware gimmick or cultural innovation? Technological, cultural, and social foundations of the Japanese video game industry. Research Policy, 32(3), 423-444.

Arakji, R. Y., \& Lang, K. R. (2007). Digital consumer networks and producer-consumer collaboration: Innovation and product development in the video game industry. Journal of Management Information Systems, 24(2), 195-219.

Asgari, N., Nikbakhsh, E., Hill, A., \& Farahani, R. Z. (2016). Supply chain management 1982-2015: A review. IMA Journal of Management Mathematics, 27(3), 353-379.

Ataseven, C., \& Nair, A. (2017). Assessment of supply chain integration and performance relationships: A meta-analytic investigation of the literature. International Journal of Production Economics, 18(5), 252-265.

Badrinarayanan, V. A., Sierra, J. J., \& Martin, K. M. (2015). A dual identification framework of online multiplayer video games: The case of massively multiplayer online role playing games (MMORPGs). Journal of Business Research, 68(5), 1045-1052.

Balland, P.-A., Belso-Martínez, J. A., \& Morrison, A. (2016). The dynamics of technical and business knowledge networks in industrial clusters: Embeddedness, status, or proximity? Economic Geography, 92(1), 35-60.

BBC. (2019). Gaming worth more than video and music combined. BBC News, 3 January 2019. https:// www.bbc.com/news/technology-46746593.

Broekhuizen, T. L. J., Lampel, J., \& Rietveld, J. (2013). New horizons or a strategic mirage? artist-leddistribution versus alliance strategy in the video game industry. Research Policy, 42(4), 954-964.

Büyüközkan, G., \& Göçer, F. (2018). Digital supply chain: Literature review and a proposed framework for future research. Computers in Industry, 97, 157-177. 
CABS. (2018). The association of business schools' journal quality guide. Chartered Association of Business Schools. https://charteredabs.org/academic-journal-guide-2018/.

Catalan, M., \& Kotzab, H. (2003). Assessing the responsiveness in the Danish mobile phone supply chain. International Journal of Physical Distribution and Logistics Management, 33(8), 668-685.

Çeltek, E. (2010). Mobile advergames in tourism marketing. Journal of Vacation Marketing, 16(4), 267-281.

Cenamor, J., Usero, B., \& Fernández, Z. (2013). The role of complementary products on platform adoption: Evidence from the video console market. Technovation, 33(12), 405-416.

Cennamo, C., \& Santalo, J. (2013). Platform competition: Strategic trade-offs in platform markets: Platform Competition. Strategic Management Journal, 34(11), 1331-1350.

Chiaravutthi, Y. (2007). Predatory pricing with the existence of network externalities in the laboratory. Information Economics and Policy, 19(2), 151-170.

Christopher, M. (2005). Logistics and supply chain management: Creating value-adding networks (3rd ed.). Harlow: Financial Times/Prentice Hall.

Christopher, M., \& Peck, H. (1997). Managing logistics in fashion markets. The International Journal of Logistics Management, 8(2), 63-74.

Chung, C., Dawande, M., Rajamani, D., \& Sriskandarajah, C. (2011). A short-range scheduling model for blockbuster's order-processing operation. Interfaces, 41(5), 466-484.

Claussen, J., Essling, C., \& Kretschmer, T. (2015). When less can be more - Setting technology levels in complementary goods markets. Research Policy, 44(2), 328-339.

Clements, M. T., \& Ohashi, H. (2005). Indirect network effects and the product cycle: Video games in the U.S., 1994-2002". Journal of Industrial Economics, 53(4), 515-542.

Cohen, S. (1984). ZAP!: The rise and fall of atari. Philadelphia Pa: Xlibris Corporation.

Corts, K. S., \& Lederman, M. (2009). Software exclusivity and the scope of indirect network effects in the U.S. home video game market. International Journal of Industrial Organization, 27(2), $121-136$.

Cox, J. (2014). What makes a blockbuster video game? an empirical analysis of us sales data: What makes a blockbuster video game? Managerial and Decision Economics, 35(3), 189-198.

Cox, J. (2017). Play it again, Sam? Versioning in the market for second-hand video game software. Managerial and Decision Economics, 38(4), 526-533.

Cox, J., \& Kaimann, D. (2015). How do reviews from professional critics interact with other signals of product quality? evidence from the video game industry: Interaction of professional critic reviews. Journal of Consumer Behaviour, 14(6), 366-377.

Cui, G., Lui, H.-K., \& Guo, X. (2012). The effect of online consumer reviews on new product sales. International Journal of Electronic Commerce, 17(1), 39-58.

Cunningham, D. C. (2001). The distribution and extent of agrifood chain management research in the public domain. Supply Chain Management: An International Journal, 6(5), 212-215.

De Prato, G., Feijóo, C., Nepelski, D., Bogdanowicz, M., \& Simon, J. P. (2010). Born digital/grown digital: Assessing the future competitiveness of the EU video games software industry. JRC Scientific and Technical Report, 2010, 24555.

de Vaan, M. (2014). Interfirm Networks in Periods of Technological Turbulence and Stability. Research Policy, 43(10), 1666-1680.

Derdenger, T. (2014). Technological tying and the intensity of price competition: An empirical analysis of the video game industry. Quantitative Marketing and Economics, 12(2), 127-165.

Derdenger, T., \& Kumar, V. (2013). The dynamic effects of bundling as a product strategy. Marketing Science, 32(6), 827-859.

Derwik, P., \& Hellström, D. (2017). Competence in supply chain management: A systematic review. Supply Chain Management: An International Journal, 22(2), 200-218.

Dew, R., \& Ansari, A. (2018). Bayesian nonparametric customer base analysis with model-based visualizations. Marketing Science, 37(2), 216-235.

Dixon, G., \& Karbolounis, P. (2000). Development and marketing of interactive entertainment software. Journal of Enterprising Culture, 8(4), 411-436.

Dubé, J.-P.H., Hitsch, G. J., \& Chintagunta, P. K. (2010). Tipping and concentration in markets with indirect network effects. Marketing Science, 29(2), 216-249.

Durgee, J. (1984). Mass marketing to fragmented markets. Planning Review, 12(5), 34-38.

Edwards, R. (2012). The economics of game publishing. IGN, 16 June , 2012. http://uk.ign.com/artic les/2006/05/06/the-economics-of-game-publishing. 
EGDF. (2011). Game development and digital growth. European Games Developer Federation. http:// www.egdf.eu.

EY. (2016). Digital supply chain: It's all about that data. EY. https://www.ey.com/Publication/vwLUA ssets/Digital_supply_chain_-_its_all_about_the_data/\$FILE/EY-digital-supply-chain-its-all-about -that-data-final.pdf.

Farahani, P., Meier, C., \& Wilke, J. (2017). Digital supply chain management agenda in the automotive supplier industry. Shopping the digital enterprise (pp. 157-172). Switzerland: Springer.

Farrand, T., Nichols, D., Rowley, T., \& Avery, M. (2006). Brands and gaming: Are you ready to play? Young Consumers, 7(2), 8-13.

Farrimond, D. (2011a). Technology that changed gaming \#2: The Commodore Amiga. Blitter and Twisted (blog), 2011. http://www.blitterandtwisted.com/2011/04/technology-that-changed-gamin g-2-the-commodore-amiga.html.

Farrimond, D. (2011b). Technology that changed gaming \#5: The 3Dfx Voodoo accelerator, Blitter and Twisted (blog), 2011. http://www.blitterandtwisted.com/2011/02/technology-that-changed-gamin g-5-3dfx.html.

Fischl, M., Scherrer-Rathje, M., \& Friedl, T. (2014). Digging deeper into supply risk: A systematic literature review on price risks. Supply Chain Management: An International Journal, 19(5/6), 480-503.

Flynn, B. B., Huo, B., \& Zhao, X. (2010). The impact of supply chain integration on performance: A contingency and configuration approach. Journal of Operations Management, 28(1), 58-71.

Francis, T. (2012). Notch on why minecraft still isn't on steam. PC Gamer, 25 July 2012. http://www. pcgamer.com//notch-on-why-minecraft-still-isnt-on-steam/.

Gallagher, S., \& Park Ho, S. (2002). Innovation and competition in standard-based industries: A historical analysis of the U.S. home video game market. IEEE Transactions on Engineering Management, $49(1), 67-82$.

Gretz, R. T. (2010). Hardware quality vs. network size in the home video game industry. Journal of Economic Behavior and Organization, 76(2), 168-183.

Healey, J., \& Moe, W. W. (2016). The effects of installed base innovativeness and recency on content sales in a platform-mediated market. International Journal of Research in Marketing, 33(2), $246-260$.

Hervas-Drane, A. (2015). Recommended for you: The effect of word of mouth on sales concentration. International Journal of Research in Marketing, 32(2), 207-218.

Herz, J. C. (1997). Joystick nation: How videogames ate our quarters, won our hearts, and rewired our minds (1st ed.). Boston: Little, Brown, and Co.

Ho, K., \& Hanssens, D. M. (2017). Advertising and word-of-mouth effects on pre-launch consumer interest and initial sales of experience products. Journal of Interactive Marketing, 37, 57-74.

Hoberg, P., Krcmar, H., Oswald, G., \& Welz, B. (2017). Skills for digital transformation. In Technical university of munich, chair for information systems, Study. Technical University of Munich. http:// www.i17.in.tum.de/fileadmin/w00btn/www/IDT_Skill_Report_2015.pdf.

Kaufmann, L., Carter, C. R., \& Rauer, J. (2016). The coevolution of relationship dominant logic and supply risk mitigation strategies. Journal of Business Logistics, 37(2), 87-106.

Keathley-Herring, H., Van Aken, E., Gonzalez-Aleu, F., Deschamps, F., Letens, G., \& Orlandini, P. C. (2016). Assessing the maturity of a research area: Bibliometric review and proposed framework. Scientometrics, 109(2), 927-951.

Kempf, D. S. (1999). Attitude formation from product trial: distinct roles of cognition and affect for hedonic and functional products. Psychology and Marketing, 16(1), 35-50.

Kim, J.-H., Prince, J., \& Qiu, C. (2014). Indirect network effects and the quality dimension: A look at the gaming industry. International Journal of Industrial Organization, 37, 99-108.

KPMG. (2019). Supply chains for a digital world. KPMG. https://assets.kpmg/content/dam/kpmg/xx/ pdf/2019/03/supply-chains-for-a-digital-world.pdf.

Kuo, A., Lutz, R. J., \& Hiler, J. L. (2016). Brave new world of warcraft: A conceptual framework for active escapism. Journal of Consumer Marketing, 33(7), 498-506.

Kuo, A., Hiler, J. L., \& Lutz, R. J. (2017). From super mario to skyrim: A framework for the evolution of video game consumption: A framework for the evolution of video game consumption. Journal of Consumer Behaviour, 16(2), 101-120.

Lambert, D. M., \& Pohlen, T. L. (2001). Supply chain metrics. The International Journal of Logistics Management, 12(1), 1-19. 
Leiras, A., De Brito Jr, I., Queiroz Peres, E., RejaneBertazzo, T., \& Yoshizaki, H. T. Y. (2014). Literature review of humanitarian logistics research: Trends and challenges. Journal of Humanitarian Logistics and Supply Chain Management, 4(1), 95-130.

Li, F., \& Yi, Z. (2017). Trial or no trial: Supplying costly signals to improve profits: Trial or no trial: Supplying costly signals to improve profits. Decision Sciences, 48(4), 795-827.

Lurquin, M. G. (1996). Streamlining the supply chain in the pharmaceuticals industry. Logistics Information Management, 9(6), 6-10.

Mackay, T., Ewing, M., Newton, F., \& Windisch, L. (2009). The effect of product placement in computer games on brand attitude and recall. International Journal of Advertising, 28(3), 423-438.

Mai, E. S., Yang, J., \& Chen, H. (2011). Primary product network size on complementary product sales: Moderating effects of customer characteristics. International Journal of Retail and Distribution Management, 39(11), 851-866.

Marchand, A. (2016). The power of an installed base to combat lifecycle decline: The case of video games. International Journal of Research in Marketing, 33(1), 140-154.

Marchand, A., \& Hennig-Thurau, T. (2013). Value creation in the video game industry: Industry economics, consumer benefits, and research opportunities. Journal of Interactive Marketing, 27(3), $141-157$.

Markovitch, D. G., Steckel, J. H., Michaut, A., \& Philip, D. (2015). Behavioral reasons for new product failure: Does overconfidence induce overforecasts? The Journal of Product Innovation Management, 32(5), 825-841.

Maruyama, M., Flath, D., Minamikawa, K., Ohkita, K. \& Zennyo, Y. (2015). Platform selection by software developers: Theory and evidence. Journal of the Japanese and International Economies, 38, 282-303.

Mayring, P. (2000). Qualitative content analysis. Qualitative Social Research, 1(2), 20.

Mcintyre, D. P., \& Srinivasan, A. (2017). Networks, platforms, and strategy: Emerging views and next steps: Networks, platforms, and strategy. Strategic Management Journal, 38(1), 141-160.

Mckone-Sweet, K. E., Hamilton, P., \& Willis, S. B. (2005). The ailing healthcare supply chain: A prescription for change. Journal of Supply Chain Management, 41(1), 4-17.

Mcquilken, L., Robertson, N., Polonsky, M., \& Harrison, P. (2015). Consumer perceptions of bundles and time-limited promotion deals: Do contracts matter?: Consumer perceptions of bundles and timelimited promotion deals: Do contracts matter? Journal of Consumer Behaviour, 14(3), 145-157.

Meagher, K., \& Teo, E. G. S. (2005). Two-part tariffs in the online gaming industry: The role of creative destruction and network externalities. Information Economics and Policy, 17(4), 457-470.

Melcer, E., Nguyen, T.H., Chen, Z., Canossa, A., El-Nasr, M. \& Isbister, K. (2015). Games research today: Analyzing the academic landscape 2000-2014. In proceedings of the 10th international conference on the foundations of digital games (FDG 2015), Pacific Grove, CA, USA.

Newzoo. (2018). Mobile revenues account for more than 50\% of the global games market as it reaches $\$ 137.9$ Billion in 2018. https://newzoo.com/insights/articles/global-games-market-reaches-137-9billion-in-2018-mobile-games-take-half/.

Olsen, L. E., \& Lanseng, E. J. (2012). Brands in texts: Attitudinal effects of brand placements in narrative fiction. Journal of Brand Management, 19(8), 702-711.

Pan, G. (2017). A dominant logic view of managing IT innovation. Journal of Information Technology Management, 28(4), 1-17.

Parfitt, B. (2015). Opinion: Retail vs steam. MCV develop, 26 November 2010. http://www.mcvuk.com/ news/read/opinion-retail-vs-steam.

Patton, M. Q. (2002). Qualitative research and evaluation methods. USA: Sage.

Peticca-Harris, A., Weststar, J., \& McKenna, S. (2015). The perils of project-based work: Attempting resistance to extreme work practices in video game development. Organization, 22(4), 570-587.

Prajogo, D., \& Olhager, J. (2012). Supply chain integration and performance: The effects of long-term relationships, information technology and sharing, and logistics integration. International Journal of Production Economics, 135(1), 514-522.

Prieger, J. E., \& Hu, W.-M. (2012). Applications barrier to entry and exclusive vertical contracts in platform markets. Economic Inquiry, 50(2), 435-452.

Ramcharran, H. (2006). Inter-firm linkages and profitability in the automobile industry: The implications for supply chain management. Journal of Supply Chain Management, 37(4), 11-17.

Reyes, P., Raisinghani, M. S., \& Singh, M. (2002). Global supply chain management in the telecommunications industry: The role of information technology in integration of supply chain entities. Journal of Global Information Technology Management, 5(2), 48-67. 
Rysman, M. (2009). The economics of two-sided markets. Journal of Economic Perspectives, 23(3), 125-143.

Sacco, D. (2014). PC games have surpassed console games globally. PCR Retail, 25 April 2014. http:// www.pcr-online.biz/news/read/pc-games-have-surpassed-onsole-games-globally/033849.

Schilling, M. A. (2003). Technological leapfrogging: Lessons from the US video game console industry. California Management Review, 45(3), 6-32.

Song, H., Jung, J., \& Cho, D. (2017). Platform competition in the video game console industry: Impacts of software quality and exclusivity on market share. Journal of Media Economics, 30(3), 99-120.

Spina, G., Caniato, F., Luzzini, D., \& Ronchi, S. (2016). Assessing the use of external grand theories in purchasing and supply management research. Journal of Purchasing and Supply Management, 22(1), 18-30.

Statista. (2018). Average prices for apps in the Apple App Store as of September 2018 (in U.S. dollars). https://www.statista.com/statistics/267346/average-apple-app-store-price-app/.

Steiner, M., Wiegand, N., Eggert, A., \& Backhaus, K. (2016). Platform adoption in system markets: The roles of preference heterogeneity and consumer expectations. International Journal of Research in Marketing, 33(2), 276-296.

Stewart, A. C., Williams, J., Smith-Gratto, K., \& Sloan Black, S. (2011). Examining the impact of pedagogy on student application of learning: Acquiring, sharing, and using knowledge for organizational decision making. Decision Sciences Journal of Innovative Education, 9(1), 3-26.

Storz, C., Riboldazzi, F., \& John, M. (2015). Mobility and innovation: A cross-country comparison in the video games industry. Research Policy, 44(1), 121-137.

Sun, J., \& Tan, R. (2012). Method for forecasting DI based on TRIZ technology system evolution theory. International Journal of Innovation and Technology Management, 9(2), 125-137.

Sun, L., Rajiv, S., \& Chu, J. (2016). Beyond the more the merrier: The variety effect and consumer heterogeneity in system markets. International Journal of Research in Marketing, 33(2), 261-275.

Sweeney, T. (2018), Announcing the Epic Games Store. Unreal Engine (blog), 4 December 2018. https:// www.unrealengine.com/en-US/blog/announcing-the-epic-games-store.

Tassi, P. (2018). 'Fortnite' developer epic is launching a huge steam competitor with a better cut for devs. Forbes, 4 December 2018. https://www.forbes.com/sites/insertcoin/2018/12/04/fortnite-developerepic-is-launching-a-huge-steam-competitor-with-a-better-cut-for-devs/.

Teipen, C. (2008). Work and employment in creative industries: The video games industry in Germany, Sweden and Poland. Economic and Industrial Democracy, 29(3), 309-335.

Teipen, C. (2016). The implications of the value chain and financial institutions for work and employment: Insights from the video game industry in Poland, Sweden and Germany: Implications of the value chain and financial institutions. British Journal of Industrial Relations, 54(2), 311-333.

Thomes, T. P. (2015). In-house publishing and competition in the video game industry. Information Economics and Policy, 32, 46-57.

Vlasimsky, S. (2003). Supply chain management: changing the status quo in chemicals. Chemical Market Reporter, 264(17), 19-29.

Wadley, G. Gibbs, M., Hew, K. \& Graham, C. (2003). Computer Supported Cooperative Play, "Third Places" and Online Videogames. In S. Viller \& P. Wyeth (Eds), Proceedings of the 30th Australian conference on computer human interaction (Brisbane, 26-28 November 2003), 238-241. Brisbane, University of Queensland.

Waterman, D., \& WookJi, S. (2012). Online versus offline in the united states: Are the media shrinking? The Information Society, 28(5), 285-303.

Wengi, S., \& Altinkemer, K. (2008). A multigeneration diffusion model for IT-intensive game consoles. Journal of the Association for Information Systems, 9(8), 442-461.

Werning, S. (2019). Disrupting video game distribution: A diachronic affordance analysis of Steam's platformization strategy. Nordic Journal of Media Studies, 1(1), 103-124.

Yao, Y., Dresner, M., \& Palmer, J. W. (2009). Impact of boundary-spanning information technology and position in chain on firm performance. Journal of Supply Chain Management, 45(4), 3-16.

Yin-Poole, W. (2013). Sega sues bankrupt THQ for £630k over Company of Heroes 2 Steam pre-orders, Eurogamer.net, 10 July 2013. http://www.eurogamer.net/articles/2013-07-10-sega-sues-bankruptthq-for-630k-over-company-of-heroes-2-pre-orders.

Yu, W., Jacobs, M. A., Salisbury, W. D., \& Enns, H. (2013). The effects of supply chain integration on customer satisfaction and financial performance: An organizational learning perspective. International Journal of Production Economics, 146(1), 346-358. 
Zackariasson, P., \& Wilson, T. L. (Eds.). (2012). The video game industry: Formation, present state, and future (1st ed.). New York: Routledge.

Zairi, M. (1998). Best practice in supply chain management: The experience of the retail sector. European Journal of Innovation Management, 1(2), 59-66.

Zhu, F., \& Zhang, X. (2010). Impact of online consumer reviews on sales: The moderating role of product and consumer characteristics. Journal of Marketing, 74, 133-148.

Zinn, W., \& Goldsby, T. J. (2019). Supply chain plasticity: Redesigning supply chains to meet major environmental change. Journal of Business Logistics, 40(3), 184-186.

Zufryden, F. (2007). An integrated virtual store-based approach for price determination before product launch. International Journal of Electronic Commerce, 11(4), 79-99. 